\title{
Introduction: How can I keep from singing ... and dancing?
}

Enjoy yourself it's later than you think Enjoy yourself while you're still in the pink.

The years go by as quickly as a wink Enjoy yourself, enjoy yourself It's later than you think.

Madness, 'Enjoy Yourself (It's Later Than You Think)'

FOR MANY YEARS popular music was looked down upon in academia, though few matched Hugo Reimann's dismissive comment that it embodied 'the lowest musical instincts of the masses addicted to arsehole art.' ${ }^{1}$ From the 1960s onwards this changed dramatically as academics from various disciplines history, musicology, sociology and others - started to pay serious attention to popular culture in general and popular music in particular. $^{2}$ As a consequence, there has been a growing number of books, articles and $\mathrm{PhDs}$ devoted to various aspects of popular music. However, it remains the case that few attempts have been made to provide a broader overview. This is disappointing, as Dave Russell's outstanding pioneering study, Popular music in England, 1840-1914 was first published over thirty years ago. ${ }^{3}$ Given the sheer volume of material, primary and secondary, not to mention conceptual complexities, it is not entirely surprising. Ignoring Johnny Mercer's observation - 'fools rush in where wise men never go' - From Mummers to Madness is a social history of popular music in England from the late-eighteenth century to the late-twentieth, which explores the popular songs 
and dances, from Georgian to Elizabethan England, and the meanings they had at the time.

The importance of music is difficult to overstate. As historian R W Malcolmson noted, it was the most accessible and democratic of the creative arts, with the ability to give expression to a range of fundamental emotions. ${ }^{4}$ From a different perspective, musicologist, Philip Tagg emphasised how music and dance are 'particularly suited to expressing the affective and corporeal identity of individuals and communities in relationship to themselves and each other, and to their social, as well as their physical surroundings, and stressed the need to understand music in its specific socio-cultural environment. ${ }^{5}$ Almost everyone could sing or dance - albeit with varying degrees of skill and many people were competent performers on fiddles and flutes, cornets and concertinas. The extent of informal singing and dancing can never be measured with accuracy, but a wide range of anecdotal evidence bears witness to the continuing popularity of singing round the piano at home or a 'knees up' in the local ale house, pub or club. Further, a growing number of people could experience music at various venues, from travelling shows to impromptu penny gaffs, from music halls and variety theatres. as well as in dancing booths, dancing saloons and later dance halls. In the twentieth century the growth of the record industry, the boom in film (especially musicals) and the advent of radio and television extended the availability of popular music in increasingly accessible forms. Individually, singing, dancing or playing, provided a means of expressing a range of often profound emotions, of voicing aspirations or fears, of commenting on and coping with the vicissitudes of everyday life, and of developing creative skills and the sense of satisfaction and identity that followed therefrom. Above all, music and music-making were sources of enjoyment $-\mathrm{a}$ fact that over-serious historians too easily ignore. Collectively, these activities could create a sense of identity and give meaning to an otherwise hostile or bewildering world through a range of celebrations - familial and communal - which, through affirmation or condemnation, could either consolidate the bonds that held together local communities or help to bring about change. The 'roles' of music were many and varied, its 'purposes' equally diverse, and, as often as not, subject to dispute. What cannot be denied is the ubiquity of popular 
music and music-making and its far-reaching significance in day-to-day life.

\section{From Mummers to Madness: the chronological framework}

If the purpose of From Mummers to Madness is simply stated, three important sets of questions remain. The first set relates to the time frame. There is a fuzziness about the terminal dates of the period covered because there is no obvious starting point, no obvious conclusion. In large measure this stems from the nature of the subject matter. Popular music, in its many forms, constantly evolved and defied simple chronological compartmentalising. Nonetheless, the book is organised chronologically, with three thematic strands running through the different time periods. This framework encompasses 'the three 'moments' of radical situational change, identified by Richard Middleton. ${ }^{6}$ - the bourgeois revolution of the years from the late-eighteenth century to the 1840s, the mass culture of the years from the late-nineteenth century to the 1930 s and the pop culture of the post-World War II years - but with a modified periodisation. Broadly, the book falls into two parts, with the turn of the twentieth century as the dividing point, reflecting the changing technological basis of both music-making and music-consumption. Each part is further sub-divided. In light of Tagg's observation, and to avoid repetition later, a brief outline of the key characteristics of each section will be given to indicate the framework in which popular music developed: responding to, commenting on but also helping to shape attitudes and events.

Section 1 covers the 'pre-music hall' period from c.1770s to c.1840s, commonly associated with the first 'Industrial Revolution,' but better understood in terms of urbanization and commercialization. Urbanization, that steady long-term shift of population from hamlet and village to town and city, had a profound effect in terms of the scale and location of music making and consumption. Commercialization, was a wide-ranging phenomenon, encompassing agriculture, industry and services, including leisure provision, and was linked to improvements in transportation and communication, furthering integration in economic but also ) in cultural terms. Equally important, though still a contentious issue, was a slow, 
often irregular improvement in working-class real earnings, which, combined with a willingness to devote some income to non-essential expenditure, turned the potential demand of a growing population into effective demand for, amongst other things, leisure.

Closely related were changes in the structure and values of society, as the old socio-economic and political order, with its emphasis on hierarchy, paternalism and (vertical) interests, was steadily replaced by a society organised more horizontally(into classes) and in which the 'moral economy,' with its notion of the 'just price,' was being replaced by ideas of the market. ${ }^{7}$ Equally important, was the ongoing redefinition of gender roles. Initially, this ideological struggle was directed more against an aristocratic 'libertine' lifestyle and code of behaviour. Increasingly, and coinciding with the concentration of working-class men and women in distinct areas of the rapidly growing towns and cities, expectations of 'being a man' were refashioned to guide the working man, as opposed to the gentleman of leisure. Acceptable codes of femininity were similarly refined to take into account the differing experiences of working and middle-class women. Finally, this period also saw a prolonged period of conflict with France in which questions of national identity and national pride loomed large.

The changes identified here were incomplete and ongoing. There were also important elements of continuity, often reflecting the strength and tenacity of popular attitudes, but there was a perceptible contrast between the England of the 1840s and the England of the 1800s, let alone that of the 1770s.

Section 2 covers the hey-day of the music-hall, from c.1840s to c.1900s and largely coincides with Victoria's reign. The process of urbanization, and indeed sub-urbanization, proceeded apace, to such an extent that by the early twentieth century 80 per cent of the population of England was classified as urban. The 'flight from the countryside' was a reality of the last quarter of the nineteenth century, even though it was often a short-distance move - from 'Lark Rise' to 'Candleford' and gave rise in some quarters to a romanticising of rural life inconceivable in contemporary France or Germany. Similarly, further developments in transportation and communication facilitated geographical mobility and increased awareness 
of regional differences as well as contributing to a sense of national, rather than local identity. Continuing economic growth and development led, not simply to a second Industrial Revolution based on chemicals and electricity, but also to the emergence of a mass consumer market in goods and services, with new means of production and modes of distribution. The organisation of capitalism also changed, though the extent of 'monopoly capitalism' is easily overstated.

After a period of apparent social equilibrium in the third quarter of the nineteenth century, there was a growing awareness of social problems, a (re)discovery of poverty, poor housing and disease. These were years of social and political tensions. Strikes and demonstrations by the unemployed in the 1880s and the early twentieth century spoke of class divisions. So too, the demand for political reform. Arguments for workingclass male enfranchisement posed difficulties for those who believed in the property basis of politics, though they could be resolved in terms of responsibility and education. Demands for female enfranchisement were far more problematic for a patriarchal society, under attack, not least by vilified 'new women' and 'bluestockings,' demanding access to higher education and the professions. Gender problems were not confined to women. The late-nineteenth century appeared to witness saw a male flight from domesticity, and a series of high-profile homosexual scandals raised fears about the threats to dominant (heterosexual) masculinity.

Finally, the international context became increasingly problematic. No longer the only industrialised nation, there was an increasing awareness of growing competition, notably from Germany and the United States of America, which in turn raised questions about the virility of the nation and its inhabitants. Rivalry with other 'Great Powers' was also a feature of these years. The size of the British Empire grew spectacularly but the years of high imperialism were also years of tension with France and Russia, even Germany. Worse, conflict in South Africa, cast doubts on national status and the physical condition of the urban working classes. The fear of degeneration lurked behind Imperial bravado.

Section 3 covers the years from c.1900s to c.1950s, a period of decline for variety theatres and diversity in terms of the 
dance hall, recordings, radio, film and television. In economic terms these were difficult years. The pre-1914 years had seen a stagnation in real wages and a rise in industrial militancy. The early 1920s depression was one of the severest the country had experienced and the recovery that followed was sluggish, certainly in comparison to America, though, as a consequence, the Great Depression of 1929-32, was less severe than in other countries. Nonetheless, its impact in areas of traditional, export-based industries was severe. The recovery was more dynamic but the emergence of new industries, in which there were greater opportunities for women, further highlighted regional disparities. Industrial tensions, notably the General Strike, revealed a divided nation, as did another (re)discovery of poverty in the 1930s. The second world war brought an end to mass unemployment but necessitated rationing that continued into the 1950s. Post-war austerity, again, underlined the economic costs of war and reconstruction.

Both world wars were associated with social dislocation. The mobilization of women into industry, the easing of social constraints, the absence of male role models and hasty but unstable marriages created considerable short-term anxieties. The wars accelerated longer-term changes. Growing demands for women's rights, coupled with a greater awareness of the harshness of life, especially for working-class women, led to a reassessment of gender roles and the nature of marriage, which challenged the assumptions of Victorian patriarchy. Being a man was less clear cut in the light of wartime carnage, but there were fears that the feminization of society would undermine familial and societal stability. Tensions between advocates of change and defenders of the status quo played out in different spheres, including the cultural. The seemingly irresponsible 'flapper,' dancing the Charleston in the 1920s, or the teddy boy-cum-juvenile offender, jiving in the 1950s, was seen as living manifestations of wider social problems.

Nor was the international context any brighter. The unresolved international tensions after the Treaty of Versailles were a continued source of anxiety, compounded by the emerging challenges to empire, notably in Ireland and India. Finally, as America emerged as the dominant world economic and financial power, clearly the case after the second world 
war, it was also seen as a cultural threat. Mass democracy, mass education and mass culture posed challenges to the (selfappointed) guardians of cultural values. The new forms of communication - radio, later television, films and records became important sites of change and conflict.

Section 4 covers the years from the mid-1950s to the late1970s/early 1980s. Many of the earlier technological changes were further refined with the appearance of portable radios and record players, tape-recorders, cassettes and compact discs. In economic terms the third quarter of the twentieth century was associated with growing economic prosperity, full employment and the growth of mass consumerism, especially associated with teenagers, but the economic consensus ('Butskellism') crumbled under the pressure of the dramatic short-term rise in oil prices from 1973 onwards, and more general concerns with 'stagflation.' In social terms the absence of fathers during the war, the sharp increase in divorces immediately after the war and a rise in juvenile delinquency created interlocking anxieties about marriage and the family, which were increasingly associated with the perceived threats of youth sub-cultures, from teddy boys and mods, to skinheads and punks. In turn, they fed into fears about the threat posed by the 'Americanization' of popular culture.

Finally, these years saw considerable anxiety surrounding the loss of empire and the growing numbers (exaggerated in the popular imagination) of new commonwealth immigration. The African-Caribbean community was never homogenous. Class and gender divisions were important. So too were generational differences. Those born in the Caribbean and emigrating to Britain in the late-1940s and 1950s were very conscious of the economic problems besetting the islands and came with a particular view of Britain shaped by their education. Despite considerable, often overt, prejudice, there was a greater willingness to tolerate discrimination than found among their daughters and sons. The first British-born generation were more conscious of their distinct 'black British' identity, expressed, by some, in Rasta culture and politics. Generational differences were also found in the 'white' population. The postwar generation grew up in an overwhelmingly white society, whereas their children did so in a clearly visible multi-ethnic society. For both generations, the meaning of being British 
(or English) could not be taken for granted and had to be negotiated in socio-political and cultural terms. Although it is oversimplistic and misleading to discuss immigration in terms of problems and conflict, racial prejudice and periodic conflict, from the Notting Hill riots of 1958 to the inner-city riots of 1981 , had a profound effect on society, and specifically on the development of popular music.

Running through all four sections are three major themes, or clusters of issues. The first relates to the alleged problematic nature of working-class leisure. While precise details varied over time, there were recurring panics about the threat posed to the economic productivity, moral well-being, and even political stability, of the country if certain forms of popular music (and indeed other forms of leisure) were not contained and civilised. From Stamford bull-runners in the late eighteenth century to mods and rockers in the mid-twentieth century the authorities (moral as much as political) complained about and tried to suppress popular cultural activities. The focus on working-class leisure obscures concerns that the 'virtuous and respectable' middle-classes might also succumb to seductive but corrupting new forms of music. Closely related to this is the recurring concern with the alleged threat to English culture posed by a variety of external, alien and uncivilised cultural forces and exacerbated by commercialization. Time and again references were made to an 'authentic' popular English culture. In fact, there was never an authentic, non-commercial indigenous popular music. Fusion - of commercial and non-commercial music as much as of different musical cultures - was a central feature of the evolution of popular music in England.

This relates to the second theme:popular music and identity. Popular music was intimately intertwined with notions of identity, be they parochial or national. The importance of the village or parish was not confined to eighteenth-century mummers or morris dancers but was to be seen in many of the songs of the Kinks and some of the early songs of the Beatles. Notions of Englishness were particularly important at certain times, from the Napoleonic war years, through the era of high imperialism, to the war years of the twentieth century. And there were other times when English culture was seen to be threatened by vulgar American invaders. Finally, music 
and identity were central for members of various sub-cultures, most obviously, teddy boys in the 1950s, mods and rockers in the 1960s, and skinheads and punks in the 1970s but also for different generations of immigrant communities.

The third theme centres on internationalization and cultural fusion. Notwithstanding the strength of a popular mythology that celebrates the sturdy, island independence of the English, the country had always been part of a wider world, cultural and otherwise. The fortunes of the English were closely intertwined, firstly with their immediate neighbours in Scotland, Ireland and Wales (the original English empire), and secondly with members of their first and second formal empires, as part of that 'intercultural and transnational formation ... the black Atlantic,' which had such far-reaching social and cultural effects. ${ }^{8}$ Despite recurring complaints about 'alien' music, songs and dances travelled across the Atlantic as much as across the United Kingdom, and were adopted, adapted and incorporated into a dynamic popular culture, which renewed and reinvigorated itself over the decades.

\section{From Mummers to Madness: the geographical context}

The second set of questions relate to the geographical focus of this study. If applying temporal boundaries to popular music is arbitrary (to the point of meaninglessness), so too is applying geographical boundaries. There was a long-standing, shared popular musical culture that transcended the boundary between England and Scotland. Similarly, the music-hall and variety-theatre circuits of the nineteenth and twentieth centuries did not stop at national borders but stretched to Aberdeen in the north of Scotland and to Cork in the south of Ireland. Equally, population movements were also cultural movements. The Welsh families travelling to the nineteenthcentury iron and steel works of Cleveland brought their poetry and their music and were instrumental in establishing eisteddfau in Middlesbrough. The Irish, as much in the 1950s and 1960s as in the 1840s and 1850s, brought their songs and dance music to many parts of mainland Britain, maintaining a link with places and family left behind, creating a sense of identity in the new and often alien environment. but also fusing with and modifying the existing popular music. ${ }^{9}$ So too did 
immigrants from the Caribbean. There were local variations, to be sure, that reflected the strength of local tradition in all parts of the United Kingdom but, more importantly, there were constant and complex cultural flows that made a nonsense of geographical borders. The focus on England is, therefore, partly a convenience, partly a reflection of authorial preference - particularly in the choice of detailed evidence from London, the north-east of England and the West Riding of Yorkshire - and partly a pragmatic decision reflecting the balance of historical research and popular writing and the limitations of space. ${ }^{10}$ But if at times there is more than England on offer, there are others when there is less. There are only limited references to Devon and Cornwall, and Cumberland and Westmorland.

\section{From Mummers to Madness: what is popular music?}

The third, and most intractable, problem is one of definition. What is 'popular music'? The ongoing debate bears witness to the problematic nature of the term and the continuing absence of a widely-accepted definition, reflected in Cole's reference to 'the deadlocks of definition' and Parker's observation on 'the elusive, perhaps delusive' attempt to find a precise definition. ${ }^{11}$ It is tempting to reject the attempts at theorising and fall back on a 'common-sense' empiricism, but this would be a mistake that effectively turns a blind eye to complex but important issues. ${ }^{12}$ The arguments in this book are based on two sets of propositions.

First, popular music is not a single, coherent category but embraces a range of musical forms that vary over time and cannot be understood neither in terms of class ownership nor of a high art/low art dichotomy. Like any popular cultural form, it is unstable (in the sense of being subject to constant change, both internal and external) and lacking in coherence to the point of being contradictory at certain times. Further, it is negotiated, rather than pre-determined, and is the product of complex interactions influenced by class, gender, race and age within a broad socio-economic and political framework and in specific time periods.

Second, because it is negotiated, popular music can only be understood in its historical contexts. Popular music, like any 
popular cultural form, is not simply a product of underlying socio-economic forces, or part of a superstructure, but can be both cause and effect of change. Further, because it is the product of complex struggles regarding its form and content, popular music is neither necessarily confrontational nor conformist. The 'meaning' of popular music is complex and multi-layered, dependent partly on performer/producer intent and partly upon audience response.

Such an approach may be criticised (with some justification) for its 'conceptual messiness' but, perhaps, as Tagg observed in an earlier discussion, this may be 'one of its most useful characteristics. ${ }^{13}$

Considerations of space necessitate decisions on content. Classical concerts, operas and operettas have been excluded, except in so far as extracts (overtures or 'hit songs') found their way onto the stage. ${ }^{14}$ Sacred music has also been excluded, even though Victorian choral societies attracted considerable numbers of performers and audience members from across the social spectrum. Similarly, limited references are made to brass bands, despite their importance in regions such as Yorkshire, and to concertina bands, handbell ringers, let alone Jiggerum Juggerum bands. The two folk revivals, jazz and ragtime, will not be covered in detail, even though both can be seen as popular and important musical forms. More specifically, and particularly in part 4, certain aspects of popular music, Heavy Metal, Glam Rock and Prog Rockare not discussed; and this is the only mention of ABBA! Perhaps the most significant omission is a detailed consideration of bhangra and other forms of south-Asian popular music. Such omissions will disappoint some and anger others, but hopefully they will provoke debate.

\section{Some problems of evidence}

It is important to recognise the limitations of the available sources. The first set of problems relate to the range of popular songs and dances. The breadth of research and the extent of digitalisation means that there is more (and more accessible) primary material than ever before. The sheer volume of, for example, music-hall songs is both exhilarating and overwhelming; so too, the detail to be found in the pages of the local and trade press. However, there is a danger of 
assuming that these treasure-troves provide us with a clear and accurate guide to music-making and music consumption in the past. In fact, and clearly more so as one goes back in time, we have an incomplete guide. Much material was ephemeral and simply did not survive, or if it did, owed much to chance. In some cases, only the title of a song or tune has survived and, even when there are words and music, we do not know how widely a song was sung or a tune played, particularly in times when copyright protection was weak and music was easily and frequently pirated. Looking at the early nineteenth, let alone the late eighteenth-century, when there was a stronger oral/aural tradition and printed material more ephemeral, the gaps in our basic knowledge are considerable. But even the seemingly information-rich twentieth century has its problems. For example, the 'charts', especially in their early years, were based on very limited returns; and even when the coverage was improved, independent retailers went below the radar. Again, it is very difficult to establish the frequency with which pieces were played in the various 'palaises,' let alone in the town and village halls or pubs and clubs.

Nor was performance straightforward. Songs are more than the tune and the lyrics, dance tunes more than notes. With songs, in particular, the combination of words and music is crucial. Stirring calls to arms ('A Nation Once Again') can be enhanced; comic lyrics heightened ('If It Wasn't for the 'Ouses in Between'); and even banal lyrics can be transformed by a simple but evocative tune ('Danny Boy'). All too often, we have little or no idea how the music was performed, notwithstanding comments in the local press. We do not know how the early music-hall stars, such as Sam Cowell or Clement Scott sounded. ${ }^{15}$ Similarly, the sound of the much-vaunted Wombwell menagerie band must remain a mystery. Nor are these problems 'solved' with the advent of recording and filming. The technical limitations of early recordings are well known, perhaps less well known are the restrictions imposed by early filming with a single, fixed camera. ${ }^{16}$ Additionally, there is the issue of deliberate censorship of image - notably the decision to restrict coverage of the early Elvis to his upper body.

A further complication is performer intent. Several historians have analysed the lyrics of eighteenth-century 
ballads, nineteenth-century music-hall songs and twentiethcentury protest songs (among others) to uncover meaning. In certain cases - for example, social-commentary industrial ballads, such as 'The Cotton Lords of Preston' - interpretation is relatively straightforward, but in others, for example 'Wait Till the Work Comes Round,' less so. And then there is the question of innuendo, be it political or sexual. As the regular complaints of Victorian music-hall proprietors make clear, there was often a significant difference between the lyrics submitted by an artist and the actual performance. If half of the anecdotes relating to Marie Lloyd or Max Miller are to be believed - and they probably shouldn't - a nod or a wink, not to mention a minor textual adjustment, could render a seemingly respectable song risqué, even indecent. ${ }^{17}$

Lastly, there are issues relating to audience response for which evidence is both scant and difficult to interpret. Does applause for a song indicate approval of the overall performance including the sentiments contained in the lyrics? The applause for the Great MacDermott probably reflected sympathy for his political and patriotic songs but could the same be said of that Hyde Park audience, applauding the Rolling Stones? Was it approving the misogyny of some of the lyrics? Or simply responding to the showmanship of Mick Jagger? In fact, did audiences (themselves not homogenous) take any 'message' intended by the songwriter and/or the performer? Two-Tone bands intended to provide music to dance to and lyrics to ponder: their audiences generally did the former, but did they do the latter? After all, much of the attraction of rock 'n' roll or northern soul, was that it was music to dance to and enjoy, rather than lyrics to be listened to and analysed. These problems should not be minimized but, as in any form of history, the evidence, carefully assessed still allows for meaningful, if tentative, conclusions to be drawn.

There is a further problem which relates to the overt and offensive sexist, homophobic and racist language to be found in certain song lyrics and so forth. Such language if uttered or endorsed today would be unacceptable. Some would argue that simply repeating the sexism or racism of the past is equally unacceptable and should not happen. The approach in this book, to include the language of the day, has been adopted 
for two reasons. Firstly, a full appreciation of popular culture, at any point in time, can only be achieved by recognising the range of values and attitudes that existed and the language that was used at the time. To excise certain words or phrases would be to distort the past with no benefit to the present; because, secondly, only by appreciating the extent and tenacity of support for sexist, homophobic and racist ideas in the past can one hope to understand the persistence of such attitudes today. To understand is not to endorse or condone but, crucially, is an avenue to change.

Finally, and without minimizing its multi-faceted importance, it remains the case that popular music has always been, for the vast majority of men and women, irrespective of class, creed and ethnicity, about enjoyment and escape from humdrum realities, the drudgery and tedium of quotidian life. Popular music was (and is) fun - and a history of popular music should be the same. In the words of Madness: 'Enjoy yourself! It's later than you think. ${ }^{\prime 18}$

\section{Endnotes}

1 Cited in P Tagg, Music's Meanings: a modern musicology for non-musos, New York \& Huddersfield, Mass Media Music Scholars' Press, 2013, p.99

2 For example, the Centre for Contemporary Cultural Studies was set up in 1964, Popular Music and Society first appeared in 1971 and the Social History Society was founded in 1976. The commercialization of leisure in the eighteenth century was associated with the growth of a middle-class with cultural as well as political aspirations. The classic statement is J H Plumb, The Commercialization of Leisure in Eighteenth Century England, University of Reading, 1973 but, more generally, see also P Earle, The Making of the English Middle Class, London, 1989 and L Davidoff \& C Hall, Family Fortunes: Men and women of the English middle class, 1780-1850, London, Hutchinson, 1987. Early general histories of leisure include R W Malcolmson, Popular Recreation in English Society, 1700-1850, Cambridge University Press, 1973, H Cunningham, Leisure in the Industrial Revolution, London, Croom Helm, 1980, S G Jones, Workers at Play: a social and economic history of leisure, 1918-1939, London, Routledge \& Kegan Paul, 1986 and J Walvin, Leisure and Society, 1750-1950, London, Longmans, 1987

3 D Russell, Popular music in England, 1840-1914. A social history, Manchester University Press, 1987. See also L Bristow-Smith, A History of Music in the British Isles, volume 2: Empire and Aftermath, London, Letterworth Press, 2017, 
which covers the nineteenth and twentieth centuries but attempts a survey of all forms of music. There is a considerable amount of information, but the approach is essentially descriptive, and such is the author's ambitious intent that in-depth coverage of individuals and movements is necessarily limited.

4 R W Malcolmson, Life and Labour in England, London, Hutchinson, 1981, p, 99 .

5 Tagg, Music's Meanings, pp.45-6. He elaborates on the ability of music to express a range of emotions, and even contradictory emotions at the same time. Given the complex reaction of the brain, he sees music as a holistic form of musical expression.

6 See also R Middleton, 'Continuity and change: Articulating musical meaning/re-constructing musical history/locating the 'popular', Popular Music, 5, 1, 1985, pp.6-43 at p.10ff. This is not to say that such an approach is an endorsement of Middleton's analysis with its debt to Mandel's model of the growth of industrial capitalism. See R. Middleton, Studying Popular Music, Milton Keynes, Open University Press, 1995, pp. 11-16, especially p.15.

7 The response to such changes can also be seen in some of the poetry of John Clare and certain melodramas.

8 P Gilroy, The Black Atlantic: Modernity and Double Consciousness, London, Verso, 1999, p. ix

9 Additionally, as they returned 'home' they also brought a new music to Ireland.

10 There are parts of the United Kingdom, notably north Wales and, to a lesser extent, the Scottish Highlands that have not been as extensively covered in recent research. In contrast, such is the volume of material relating to popular music in Ireland that it would merit a volume in its own right.

11 H N Parker, 'Towards a Definition of Popular Culture,' History and Theory, 50 (May 2011), pp.147-70 and R Cole, 'Notes on troubling 'the popular', Popular Music, vol.37/3, 2018, pp.392-414. Many of the questions posed by the editor in the first volume of Popular Music remain unanswered today. Editor's Introduction, Popular Music, vol.1, 1981, pp.3-7. It is almost compulsory to make reference to Adorno, so see T W Adorno, 'On popular music' in Essays on Music, ed., R Leppert, Berkeley, University of California Press, 2002, pp.437-69 but for a critique see Tagg, Music's Meanings, especially pp.139-43. Among several problems with a quantitative/descriptive approach - popular is that which is liked by many people - is flawed in several ways. What is the cut-off point above which something is popular? Are all things that fall below this cut-off point necessarily not popular? And, on a more practical level, how can popularity be measured, particularly further back in time? Similarly, a qualitative/judgmental approach that defines popular culture in terms of what is left over from high culture is equally problematic. Definitions of popular culture that link it to either an ill-defined notion of 'the people' or to an equally ill-defined mass culture are unsatisfactory.

12 The questions raised in the conclusion of the editorial introduction of the very first volume of Popular Music remain pertinent. Is it possible to subsume the wide range of musical experiences within a single category of 'popular music'? And is it possible to identify suitable methods of study for this multiplicity of musical forms? The optimistically implied answers in 1981 
were 'yes'; the experience of forty years' study might appear to point to 'no.'

Popular Music, vol.1, 1981, at p.6

13 Quoted in Cole 'Notes' p. 393

14 They were also to be found in brass band repertoires.

15 Though many agreed that Scott's repertoire was one of 'unadulterated indecency and filth.'

16 Gus Elen is a good example. A meticulous artist, he kept notes of the choreography of each song. When he was filmed in the early 1930s, not only was his voice well past its best, but his stage performance was literally restricted by the need to remain in view of the camera. Nonetheless, to see a stage performance of 'Great Big Shame' puts a seemingly harmless comic song in a different light as Elen uses his hammer to hit the nagging wife who hen-pecked his mate!

17 Lloyd fell foul of the licensing authorities on several occasions. Having been reprimanded for including in the chorus of a song the line 'She sits among the cabbages and peas' she allegedly substituted 'leaks' for 'peas'. Likewise, she is alleged to have rendered indecent the hitherto impeccable 'Come Into the Garden Maud'.

18 The song, which dates from 1949, has been recorded by artists as varied as Prince Buster. The Specials, Jools Holland and His Rhythm and Blues Orchestra, The Supremes, Bing Crosby and Doris Day. 